\title{
A Corpus-based Study on Ditransitive Construction "Give" in English Writing
}

\author{
Mi Wang \\ Zhantan Middle School \\ Xindu District, Chengdu \\ Sichuan, China
}

\author{
Huaqing $\mathrm{He}^{*}$ \\ College of Foreign Language Education \\ China West Normal University \\ Nanchong, Sichuan, China \\ *Corresponding Author
}

\begin{abstract}
Under the framework of Goldberg's Construction Grammar, this study analyses the "give" frequency, the preference of the patient argument and errors types with the help of quantitative approach and qualitative analysis. It aims at providing senior high school students with some methods to improve their English writing proficiency and yield some suggestions on English foreign language teaching to teachers. The main findings are as follows: (1) Chinese senior high school students overuse the information type of direct objects to express advice on patient argument. However, native speakers use more types of patients; (2) in terms of different language proficiency levels, there are still divergences existing among low level and high level learners. The general tendency is that high level learners have a better understanding of "give" DC than lower learners.
\end{abstract}

Keywords-corpus; English writing; ditransitive construction "give"component

\section{INTRODUCTION}

Ditransitive Construction (DC) can be described as $\mathrm{NP}+\mathrm{V}+\mathrm{NP} 1+\mathrm{NP} 2$ in English traditional grammar [1]. This pattern contains two types of constructions: one is doubleobject construction whose sentence pattern is "Subject+ Verb+ Indirect Object+ Direct Object (SVOO)"; the other is object complement construction whose sentence pattern is "Subject+ Verb+ Object Compliment (SVOC)". The term DC appeared in this study refers to the former [2].

There are two problems addressed in this paper to be solved. One is to find out the similarities and differences on the patient argument of English "give" DC between Chinese EFL learners and native speakers; the other is to test whether there are differences on the use of "give" DC among Chinese English foreign language learners (EFL) at different levels. This paper aims at finding out the similarities and differences on the patient argument of "give" DC, investigating on the usage of "give" DC among Chinese EFL learners at different levels.

\section{LITERATURE REVIEW}

From 1970s, a number of linguists have conducted studies on English DC and have acquired a lot of

This work was supported by the Meritocracy Research Funds of China West Normal University achievements at home and abroad. In China, $\mathrm{Hu}$ (2007) did a contrastive research on English and Chinese DC based on two corpora CLEC and LOCNESS. It was found the development pattern of English DC was similar to that of native speakers by Chinese EFL learners[3]; Che (2007) did a research Contrastive Study on Grammaticalization of Chinese "Gei" and English "give", focused on what individual grammaticalization case means extended from lexical items to phrases, syntactic structures and discourses. It aimed to illustrate the grammaticalization theory by a contrastive study of English "give" and Chinese "gei" from diachronic and synchronic perspective [4]; Lu Huixia (2012) made a corpus-based comparative study of Chinese college students" acquisition of direct objects on "give" DC in which she collected a corpus made up of 251 students' English writings compared with Corpus of Contemporary American English and found Chinese EFL learners use English "give" DC in a limited way [5].

Goldberg (2000) did a heuristic experiment. He designed 16 sentences including four types of verbs, namely transitive, resultative, ditransitive and cause-motion. In this experiment, the participants were required to classify these sentences by their verb categories or construction standards [6]; Mukherhee (2005) investigated1741 DC sentences in ICEGB and finds that "give" was one of the most frequent verbs among 70 most participant words. The main difference of "give" is whether the word expresses the explicit-giving, inexplicit giving or the potential-giving which shows that "give" is the most typical verb in DC [7].

The review of previous studies on English DC at home and aboard reveals each of the previous study has its own findings. The studies at home illustrated above are mainly focusing on the frequency of using the ditransitive verbs and paying much attention to analyzing a certain argument among the three arguments. However, because of lacking comprehensive investigation, these domestic studies should be investigated deeply.

\section{RESEARCH DESIGN}

This chapter contributes to the whole thesis significantly on the account of corpus-based method adopted in the study. 


\section{A. Research Questions}

This study examines Chinese EFL learners' usage of direct objects in English "give" DC, which addresses the following questions:

- What are the overall features on patient argument "give" DC between Chinese EFL and native speakers?

- Is there any difference on the use of patient argument "give" DC among Chinese EFL learners at different levels?

\section{B. Research Instruments}

This section gives a detailed introduction to the instruments. The corpora CLEC and BROWN will be employed in this study.

1) CLEC: CLEC is the first language corpus in China and it is a part of national project: Corpus-based Analysis of Chinese Learner English. It is led by Professor Gui Shichun from Guangdong University of Foreign Studies and Yang Huizhong from Shanghai Jiao Tong University [8]. The data will be described in the following "Table I" [9].

TABLE I. MATERIAL DisTRIBUTIONS OF CLEC (GUI \& YANG, 2003:3)

\begin{tabular}{|c|c|c|}
\hline Sub-corpora & Components & $\begin{array}{c}\text { The number } \\
\text { of words }\end{array}$ \\
\hline ST2 & Senior high school students & 208088 \\
\hline ST3 & College non-English majors(CET-4) & 209043 \\
\hline ST4 & College non-English majors(CET-6) & 212855 \\
\hline ST5 & $\begin{array}{c}\text { Freshmen and sophomores of English } \\
\text { majors (CET-6) }\end{array}$ & 214510 \\
\hline
\end{tabular}

This study focuses on the features of Chinese EFL learners' use of "give" DC, and three sub-corpora ST2, ST5, and ST6 are used in it. Considering that the compositions from non-English majors are all from CET-4 and CET-6, the topics are given to the students early, in order to avoid making mistakes. Furthermore, because of the limited time, they can't look up dictionary and are more likely to be anxious than senior high school students. Therefore, this study does not select data from ST3 and ST4.

2) BROWN: The BROWN corpus is compiled by Henry Kuera and W. Nelson Francis at Brown University in 1963. It contains 500 texts and each text is consist of nearly 2000 words, altogether 1,014,312 words in the present day edited by American English. Ideally, the reference corpus to be compared is composed of texts from the same genre and had better be of the similar size. BROWN is similar to CLEC, which is considered as a collection of students' English writings used for general purpose.

3) The concordancer antconc 3.2.1: AntConc3.2.1 is free software invented by Dr. Laurence Anthony of Waseda University in Japan. It contains many useful tools, such as Concordance, Concordance Plot, File View, Clusters, Collocates, Word List, Keyword List, etc.
4) Chi-square Calculator: Chi-square Calculator is used to provide the value of Chi-square with its corresponding $\mathrm{p}$ value and the degree of freedom (i.e. “df').

\section{Research Procedures}

In this part, it mainly introduces the research procedures. Specifically, it describes the process of word list generating and the way of concordance hits extracting from "give" DC.

1) Data collection: This study takes the following steps to get the statistics this research need:

- Step1. Search for all the clauses containing the "give" verbs (including give, gives, gave, giving, given) in CLEC (sub-corpora ST2, ST5 and ST6) and BROWN

- Step2. Select the "give" DC and wipe out the non-DC "give" manually to ensure the validity.

- Step3.Analyze the frequency, percentage and Keyness $\mathrm{G}^{2}$ (i.e. log-likelihood) of the occurrence of "give" DC and classify the patient argument in DC according to their semantic properties and finally count the frequency of each category.

2) Data processing: This study analyzes the frequency, percentage and Keyness $G^{2}$ (e.g. Log-likelihood) of the occurrence on "give" DC. The value shows whether the observed differences are likely or unlikely to occur by chance. The breakpoint values of Keyness $G^{2}$ are listed in "Table II".

TABLE II. THE BREAK-POINT VALUE OF G2

\begin{tabular}{|c|c|}
\hline Keyness $^{\mathbf{2}}$ & Significance \\
\hline 15.13 & $\mathrm{P}<0.0001$ \\
\hline 10.83 & $\mathrm{P}<0.001$ \\
\hline 6.63 & $\mathrm{P}<0.01$ \\
\hline 3.84 & $\mathrm{P}<0.05$ \\
\hline
\end{tabular}

When the value is higher than 15.13 , it can be said that the difference in the use of one word arrives at a 0.0001 significance level between two corpora. When the value is between 10.38 and 15.13, it can be said that the difference on the use of one word arrives at a 0.001 significance level between two corpora. The value 3.84 is regarded as the break-point value. If a value is higher than 3.84, the difference is significant. The frequency of "give" DC and patient arguments are calculated by the concordancer AntConc3.2.1 and the software Log-likelihood Calculator.

\section{RESULTS AND DISCUSSION}

The detailed analysis focuses on the similarities and differences at different levels and the errors committed by senior high school students with "give" DC by Chinese learners will be presented in this chapter.

\section{A. General Features of Patient Argument on "Give" DC Rin CLEC and BROWN}

According to Goldberg (1995) [10], patient is a conventionally three-dimensional, physical, concrete object. 
Only with three elements, can the patient argument ensure its transitivity. In this study, the author just examines the patient argument into two categories: physical objects and nonphysical objects [11].

\section{1) The two sub-categories of physical objects}

a) living objects used as patients

CLEC: His friend gave him a big cat. (ST2)

BROWN: I'll give you a team of nine gentlemen and we'll beat you.

\section{b) Non-living objects used as patients}

CLEC: And thank you to you gave us so many good books. (ST2)

BROWN: cut down on the number of performers and give them a little room

TABLE III. PHYSICAL OBJECTS AND NON-PHYSICAL OBJECTS IN CLEC AND BROWN

\begin{tabular}{|c|c|c|c|c|c|c|}
\hline \multicolumn{2}{|c|}{} & \multicolumn{3}{|c|}{ Physical objects } & \multirow{2}{*}{$\begin{array}{c}\text { Non- } \\
\text { physical } \\
\text { objects }\end{array}$} & \multirow{2}{*}{ Total } \\
\cline { 3 - 7 } \multicolumn{2}{|c|}{} & $\begin{array}{c}\text { Living } \\
\text { objects }\end{array}$ & $\begin{array}{c}\text { Non- } \\
\text { living } \\
\text { objects }\end{array}$ & Total & \\
\hline \multirow{2}{*}{ CLEC } & Freq. & 11 & 122 & 132 & 260 & 393 \\
\cline { 2 - 7 } & Per. & $2.80 \%$ & $30.79 \%$ & $33.59 \%$ & $66.41 \%$ & $100 \%$ \\
\hline \multirow{2}{*}{ BROWN } & Freq. & 5 & 59 & 64 & 288 & 352 \\
\cline { 2 - 7 } & Per. & $1.42 \%$ & $16.76 \%$ & $18.18 \%$ & $81.82 \%$ & $100 \%$ \\
\hline \multicolumn{2}{|c|}{ LL } & +1.69 & +15.51 & +17.19 & -5.97 & \\
\hline
\end{tabular}

"Table III" describes that in CLEC, the proportions of physical objects and non-physical objects occupied are $33.59 \%$ and $66.41 \%$ as patients. In BROWN, the proportions of physical objects and non-physical objects occupied as patients are $18.18 \%$ and $81.82 \%$. Both Chinese EFL learners and native speakers are more likely to use the non-physical objects as patients in "give" DC constructions than the physical objects. Physical arguments can be divided into living objects and non-physical objects. The proportion of living objects used as patient argument is very small, only takes up $2.80 \%$ and $1.42 \%$ in CLEC and BROWN respectively.

2) Six Sub-categories of Non-physical objects: The categories of non-physical objects have six sub-categories, that is, the external conditions, internal features, information, actions, non-specific reference and idioms.

a) The category of external conditions: The category of external conditions means the agent provides the recipient with the patient as an external condition. The prototypical members in this category are related to "time", that is, "years, days, night, hours, minutes, future, chance, time, opportunity" ; "space", that is, "point, space, base , room, place, venue, field, spot, stage".

CLEC: The physical culture [wd3, 2-10] gave the students a chance to have sports and games. refuse.

BROWN: She P18 0500 didn't even give me a chance to b) The category of internal featur: The category of internal feature indicates that the agent creates internal feature to the recipient. There are a variety of types of the internal features. First of all, the patients express the psychological state of recipients namely "sense, feeling, hope, pleasure, ability". Then, the recipients provide the patients with "power, role, right, freedom, access, discretion, leverage, say, voice, authority, control, influence".

CLEC: My classmates supported me and gave me power [cc3, 3-].

BROWN: If otherwise, you will give me a pleasure.

c) The category of information: The category of information includes the direct objects about "advice" that is, "advice, suggestion, idea, tip, proposal"; the direct objects about "cause and reason", that is, "reason, excuse, grounds, cause".

CLEC: Now, I'll give you some information about our job opportunities.

BROWN: If they give him advice B07 0310 when he asks it, or if they

d) The category of action: The category of action denotes that the patients display the process of action, for example, the direct objects about the "evaluation", that is, "credit, test, contempt, assessment, rating, score, a pass, recommendation, comment, score, evaluation"; the direct objects about "encouragement" that is, "boost, incentive, endorsement, encouragement" ; the direct objects about "action", that is, "hug, smile, push, kiss, bite".

CLEC: the seller give [vp3, 1-] the people a warm welcome.

BROWN: Angelo gave him an affectionate L08 0510 smile.

e) The category of non-specific: The category of nonspecific reference refers to the pronoun "this", "that" and the what-subordinate clause or words and something like that.

CLEC: "sorry! Then give you this!"

BROWN: I give you what your dad should have given you years back.

f) The category of idioms: CLEC: I'm going to go over there and give them a piece of my mind!

BROWN: seeing old friends, G54 0050 had given his spirits a lift.

As shown above, the category of action occupies a lion's share. It expresses the native speakers have a strong tendency to use the words expressing actions, which is not the case on using of the "give" DC by Chinese EFL learners. The differences in these categories show that Chinese EFL learners' deficiency of using the patients when expressing the meaning of actions. 
B. Features of "give" DC between Chinese EFL Learners at Different Levels

For the research purpose, this study defines ST2 as low level learners, whereas ST5 and ST6 as high level learners.

1) Comparison of Verb Frequency on "give" DC between High Level and Low Level Learners: The distribution of the ditransitive verb "give" in the three subcorpora ST2, ST5 and ST6 of CLEC is shown below in "Table IV". It could be seen that the occurrence of "give" is decreasing as the English proficiency gets high.

TABLE IV. Distribution OF VERB FrequenCy “GiVE” IN SUb CORPORA OF CLEC

\begin{tabular}{|c|c|c|c|c|c|c|}
\hline $\begin{array}{c}\text { Learners } \\
\text { at } \\
\text { different } \\
\text { levels }\end{array}$ & \multicolumn{2}{|c|}{ Low level } & \multicolumn{4}{c|}{ High level learners } \\
\hline & \multicolumn{2}{|c|}{ ST2 } & \multicolumn{2}{|c|}{ ST5 } & \multicolumn{2}{c|}{ ST6 } \\
\hline give & Freq. & $\%$ & Freq. & $\%$ & Freq. & $\%$ \\
\hline & 195 & $49.62 \%$ & 115 & $29.26 \%$ & 83 & $21.12 \%$ \\
\hline
\end{tabular}

According to "Table IV", it could be seen that the percentage of high level learners of English majors ST5 and ST6 takes up $29.26 \%$ and $21.12 \%$ respectively, which are lower than that of low level learners ST2, $49.62 \%$. Meanwhile, the percentage of high level learners of English major ST5 (29.26\%) is higher than that of ST6 (21.12\%). That is to say, Chinese EFL learners with lower English proficiency level are more likely to use the "give" DC than those of higher English proficiency level.

2) Differences on the choice of patient argument on the use of "give" dc between high level and low level learners : As is mentioned and discussed in the above Section, patient argument in DC is classified into two main categories: one is physical object and the other is non-physical object. The two sub-categories of physical objects are living objects and non-living objects. The categories of non-physical objects have six sub-categories, namely, the external conditions, internal features, information, actions, non-specific reference and idioms.

From "Table V", the Log-likelihood value of " +11.55 " indicates that ST2 learners overuse the verb non-living objects patients very significantly compared with ST5 and ST6. However, the Log-likelihood values of " +1.00 " indicates ST2 learners overuse the idioms a bit. The Loglikelihood values of "-0.21", "- 0.52 ", “- 0.65 " and " -1.23 " illustrates that there exists no significant difference on the use of internal features, information, actions and non-specific reference, though ST2 learners underuse these four patients comparing to ST5 and ST6 learners. Besides, there exists a significant difference in the underuse of the external conditions patient in ST2 relative to ST5 and ST6 with the Log-likelihood value “-3.57”.
TABLE V. Distributions of PATIENT ARgument In CLEC

\begin{tabular}{|c|c|c|c|c|c|c|}
\hline \multicolumn{2}{|c|}{} & Freq. & $\%$ & Freq. & $\%$ & LL \\
\hline \multirow{2}{*}{$\begin{array}{c}\text { physical } \\
\text { objects }\end{array}$} & $\begin{array}{c}\text { living } \\
\text { objects }\end{array}$ & 9 & $4.59 \%$ & 2 & $1.03 \%$ & +4.78 \\
\cline { 2 - 7 } & $\begin{array}{c}\text { non-living } \\
\text { objects }\end{array}$ & 82 & $41.84 \%$ & 40 & $20.51 \%$ & +11.55 \\
\hline \multirow{4}{*}{$\begin{array}{c}\text { the external } \\
\text { conditions }\end{array}$} & 25 & $12.76 \%$ & 40 & $20.51 \%$ & -3.57 \\
\cline { 2 - 7 } non- & $\begin{array}{c}\text { internal } \\
\text { features }\end{array}$ & 26 & $13.27 \%$ & 32 & $16.41 \%$ & -0.65 \\
\cline { 2 - 7 } objects & information & 23 & $11.73 \%$ & 31 & $15.90 \%$ & -1.23 \\
\cline { 2 - 7 } & \begin{tabular}{c} 
actions \\
\cline { 2 - 7 }
\end{tabular} & 22 & $11.22 \%$ & 25 & $12.82 \%$ & -0.21 \\
\hline $\begin{array}{c}\text { nopecific } \\
\text { reference }\end{array}$ & 3 & $1.53 \%$ & 5 & $2.56 \%$ & -0.52 \\
\hline
\end{tabular}

To sum up, there still exist some differences on the choice of patient arguments between learners with different English proficiency levels. Learners with low English proficiency use action patients less often than advanced learners; however, they use information and knowledge patients frequently than high level learners.

3) Summary: By categorizing a variety types of words employed by Chinese EFL learners and native speakers, the preferential sequence of the patients category in CLEC is information>external condition > internal features> actions> idioms $>$ non-specific reference. The sequence of the patient argument in BROWN is action> internal features> external condition $>$ information $>$ idioms $>$ non-specific reference.

As far as the use of the patient argument is concerned, Chinese EFL learners overuse patients of information and external condition while underuse patients of action, internal features, idioms and non-specific-reference when comparing with native speakers. Advanced learners use action patient more frequently, and information and external condition patients less frequently in comparison with learners with low English proficiency. With regard to patients, the native speakers use more types of patients than Chinese EFL learners. The patients are more diversity in CLEC than those in BROWN. It reveals that Chinese EFL learners' lacking of flexibility when they are applied to different patients.

The causes can be attributed to the students' smaller vocabulary. What's more, both Chinese EFL learners and native speakers prefer to use the non-physical objects on the use of "give" DC construction. The selection of words by Chinese EFL learners is relatively single and generally. The main reasons can be attributed to language interference especially for mastering grammar rules are not comprehensive.

\section{CONCLUSION}

The final chapter will present the conclusions of this study and some pedagogical implications on L2 teaching and learning.

\section{A. Major Findings of the Study}

The major findings are summarized as follows:

For the overall features of patient argument "give" DC, the non-physical objects occupy a large proportion in both corpora, which reveals their preference of non-physical 
patient transferred on the use of "give" DC. However, native speakers use more types of patient argument than Chinese EFL learners, which reveals Chinese EFL learners' lacking flexibility and have not reached the native-like use of this construction.

In terms of different proficiency levels, high level learners tend to have a better understanding of this construction than low level learners. ST2 learners could take it for granted that patients should be concrete "things" rather than abstract results of events, so they underuse event patients. Instead, they prefer to choose most frequently used patients, such as thing, and physical objects that are related to their school life closely, such as information and knowledge patients. This means high level learners tend to use more kinds of argument patient in expressing the "giving" types DCs. They have more topics focusing on and talking about besides the teaching and learning topic compared with the senior high school students.

\section{B. Pedagogical Implications}

It is hoped that the results of this research would be helpful to teachers to get a clear picture of how to teach Chinese EFL learners English DC.

DC is the main concern of this study, which derives from the experience of languages use and enriches construction meanings in turn. This constraint generates contextual effect, namely constructional context. Language learning and language use involve both constructional context and the matching between construction and situational context [12]. This matching is controlled by communicative intention that enables constructions to connect with situational contexts. Learning a construction is a necessity to learn a language, and this learning can be acquired through interaction between linguistic structures and contexts concomitant of language use. And this interaction ensures correct use of what has been learned [13]. By recognizing the existence of constructions, it is helpful for L2 learners to avoid the claim that semantics and syntax are extended just from the specifications of main verb and other components.

From the perspective of $\mathrm{CG}$, this research gives learners inspirations to L2 teaching. Constructions, as parings of form-meaning or functions, can help students have a better understanding of English idioms effectively in the process of English acquisition, which makes students English more pure. When English teachers teach ditransitive expressions, they can explain to students the prototypical constructional meaning of DC, which is X CAUSES Y TO RECEIVE $Z$. What's more, any ditransitive construction expression is an instance of X CAUSES Y TO RECEIVE Z. It integrates the constructional senses with the components of individual ditransitive expressions [14]. It is unnecessary to emphasize the traditional grammar what the subject, predicate, indirect object and direct object is.

\section{Limitations and Suggestions}

Although the present study tries to make a comprehensive understanding of Chinese EFL learners' use of the English "give" DC, there are still some limitations needed to be paid attention to.
First, the present study only explores the similarities and differences on the use of English "give" DC. If comparisons are made between learners at different L1 backgrounds as Japanese speakers and English native speakers, the results would be more multidimensional and comprehensive.

Then, in order to guarantee the coverage of learners' frequency of vocabulary, this study restricts the investigation to a certain representative verb "give" though the verb "give" is selected with a corpus-based approach. What's more, it represents three categories of ditransitive verbs to a certain degree. Therefore, more comprehensive and extensive investigations are called for further research and analysis.

Finally, since the verbs "give" is very representative and common, Chinese EFL learners commit few errors in using them besides some spelling errors and grammar mistakes. Therefore, further researches needed to make a thorough and detailed investigation into errors made by learners.

\section{REFERENCES}

[1] Goldberg, A and D. Cascenhiser. Construction learning and second language acquisition in Catherine J. Doughty and H.L. Michael. 2003. The Handbook of Second Language Acquisition, 65-70. Oxford: Blackwell, 2008.

[2] Goldberg, A. Constructions at work: The nature of argument structure generalization. Oxford: Oxford University Press, 2006.

[3] X. W. Hu, A Corpus-based Study on English Ditransitive Construction of Chinese English Foreign Language Learners. Foreign Languages Research, 2007.

[4] J. Che, A Contrastive Study on Gammaticalization of Chinese "Gei" and English "give". M.A. dissertation, Wuhan University of Technology, 2007

[5] H. X. Lu, A Corpus-based Comparative Study of Chinese College Students' Acquisition of Direct Objects in the Ditransitive Construction of "Give". School of Foreign Language, Zhejiang Ocean University, Vol, 29, 2012.

[6] Goldberg, A. E. Patient arguments of causative verbs can be omitted the role of information structure in argument distribution [J]. Language Sciences, Vol. 23, Issues 4-5: 503-524, 2001.

[7] Mukherjee, J. English Ditransitive Verbs: Aspects of Theory, Description and a Usage-based Model [M]. Amsterdam: Editions RodopiB.V, 2005.

[8] S.C. Gui, and H.Z.Yang, Chinese Learner English Corpus. Shanghai, Shanghai Foreign Language Education Press, 2003.

[9] H.Z. Yang, S. C Gui, and D. F. Yang, Corpus-based Analysis of Chinese Learner English. Shanghai, Shanghai Foreign Language Education Press, 2005.

[10] Goldberg A. Constructions: A Construction Grammar Approach to Argument Structure [M], Chicago: The University of Chicago Press, 1995.

[11] F.R. Zhao, A Corpus-Based Study on the Features of Ditransitive Construction in Chinese EFL Learners English Writing [D], Shanghai Jiao Tong University Press, 2010.

[12] X.W. He, A Semantic Study of the Ditransitive Construction [J], Foreign Language Teaching and Research, 2009.

[13] Y. Wang, Researches on Construction Grammar [M], Shanghai Foreign Language Press, 2011.

[14] Goldberg, Adele, E. Construction: A New Approach to Language [J] Foreign Language, 2003 